\title{
Isometric handgrip does not elicit cardiovascular overload or post-exercise hypotension in hypertensive older women
}

\author{
Rafael dos Reis Vieira \\ Olher $^{1,2, *}$ \\ Danilo Sales Bocalini ${ }^{3, *}$ \\ Reury Frank Bacurau ${ }^{4}$ \\ Daniel Rodriguez ${ }^{5}$ \\ Aylton Figueira $\mathrm{Jr}^{5}$ \\ Francisco Luciano Pontes $\mathrm{Jr}^{4}$ \\ Francisco Navarro ${ }^{6}$ \\ Herbert Gustavo Simões' \\ Ronaldo Carvalho Araujo ${ }^{7}$ \\ Milton Rocha Moraes ${ }^{8}$ \\ 'Universidade Católica de Brasília, \\ Distrito Federal, ${ }^{2}$ Universidade Gama \\ Filho, Rio de Janeiro, ${ }^{3}$ Universidade \\ Nove de Julho (UNINOVE), São Paulo, \\ ${ }^{4}$ Universidade de São Paulo - Escola \\ de Artes, Ciências e Humanidades, \\ São Paulo, ${ }^{5}$ Universidade São Judas \\ Tadeu (USJT), São Paulo, Brazil, \\ 'Universidade Federal do Maranhão, \\ Maranhão, 'Universidade de São Paulo, \\ Instituto de Ciências Biomédicas, São \\ Paulo, ${ }^{8}$ Universidade Federal de São \\ Paulo - Escola Paulista de Medicina, \\ São Paulo, Brazil
}

*These authors contributed equally to this work
This article was published in the following Dove Press journal:

Clinical Interventions in Aging

4 June 2013

Number of times this article has been viewed
Background: Arterial hypertension is a serious health problem affecting mainly the elderly population. Recent studies have considered both aerobic and resistance exercises as a nonpharmacological aid for arterial hypertension treatment. However, the cardiovascular responses of the elderly to isometric resistance exercise (eg, isometric handgrip [IHG]) have not yet been documented.

Objective: The purpose of this study was to investigate cardiovascular responses to different intensities of isometric exercise, as well as the occurrence of post-isometric exercise hypotension in hypertensive elderly people under antihypertensive medication treatment.

Patients and methods: Twelve women volunteered to participate in the study after a maximal voluntary contraction test (MVC) and standardization of the intervention workload consisting of two sessions of IHG exercise performed in four sets of five contractions of a 10-second duration. Sessions were performed both at $30 \%$ of the MVC and $50 \%$ of the MVC, using a unilateral IHG protocol. Both intensities were compared with a control session without exercise. Systolic blood pressure (SBP) and diastolic blood pressure (DBP) at rest (R), during peak exercise (PE), and after 5, 10, 15, 30, 45, and 60 minutes of post-exercise recovery were evaluated.

Results: No significant changes were observed after isometric exercise corresponding to $30 \%$ MVC for either SBP (R: $121 \pm 10$; PE: $127 \pm 14$; 5 min: $125 \pm 13$; 10 min: $123 \pm 12$; 15 min: $122 \pm 11 ; 30 \mathrm{~min}: 124 \pm 11 ; 45 \mathrm{~min}: 124 \pm 10 ; 60 \mathrm{~min}: 121 \pm 10 \mathrm{mmHg}$ ) or DBP (R: $74 \pm 9$; PE: $76 \pm 6 ; 5$ min: $74 \pm 5 ; 10 \mathrm{~min}: 72 \pm 8 ; 15 \mathrm{~min}: 72 \pm 5 ; 30 \mathrm{~min}: 72 \pm 8 ; 45 \mathrm{~min}: 73 \pm 6 ; 60 \mathrm{~min}:$ $75 \pm 7 \mathrm{mmHg}$ ). Similarly, the $50 \%$ MVC did not promote post-isometric exercise hypotension for either SBP (R: $120 \pm 7$; PE: $125 \pm 11 ; 5 \mathrm{~min}: 120 \pm 9$; $10 \mathrm{~min}: 122 \pm 9 ; 15 \mathrm{~min}: 121 \pm 11 ; 30 \mathrm{~min}$ : $121 \pm 9$; 45 min: $121 \pm 9$; 60 min: $120 \pm 7 \mathrm{mmHg}$ ) or DBP (R: $72 \pm 8$; PE: $78 \pm 7 ; 5 \mathrm{~min}: 72 \pm 7$; 10 min: $72 \pm 8$; 15 min: $71 \pm 7$; 30 min: $72 \pm 8$; 45 min: $75 \pm 10$; 60 min: $75 \pm 7 \mathrm{mmHg}$ ).

Conclusion: Our data reveal that cardiovascular overload or post-exercise hypotension did not occur in elderly women with controlled hypertension when they undertook an IHG session. Thus this type of resistance exercise, with mild to moderate intensity, with short time of contraction appears to be safe for this population.

Keywords: hypertension, resistance exercise, elderly, cardiovascular response, antihypertensive medication, isometric exercise

\section{Introduction}

Hypertension is estimated to affect 1 billion people worldwide, and is associated with an increased risk of cardiovascular disease and all-cause mortality, especially in the elderly. The proportion of older adults in the American countries is steadily rising, such that the portion of the population aged 65 and older is expected to double in the next 30 years. In addition, more than half of 55-year-old people are expected to develop hypertension within 10 years. $^{1}$
Correspondence: Milton Rocha Moraes Rua Pedro de Toledo 669, Vila Clementino, São Paulo, SP, CEP 04039-032, Brazil Email mrmoraes@usp.br 
It is well established that blood pressure (BP) increases with advancing age; however, it was only in the 1990s that several guidelines began to advise physical exercise and the adoption of a healthy lifestyle to prevent arterial systemic hypertension (ASH). ${ }^{2-4}$ Nevertheless, there is little evidence regarding the effect of strength training on cardiovascular responses in this population, as well as insufficient information on the interaction between exercise and drugs used to treat $\mathrm{ASH} .{ }^{2,5,6}$

Among the effects associated with the practice of exercise, post-exercise hypotension (PEH) has been studied mainly in aerobic exercises, ${ }^{2}$ while strength exercises have been investigated less. ${ }^{7-11}$ In a recent meta-analysis on the hypotensive effects of strength exercise, Cornelissen et a ${ }^{12}$ reported favorable effects of isometric training for BP control. However, it is known that cardiovascular responses to isometric exercise (IE) depend on factors such as the volume of muscle mass involved, the duration and intensity of the IE, the number of contractions, and total workload. ${ }^{2,13}$

To the best of our knowledge, only one study has evaluated medicated hypertensive elderly people. ${ }^{14}$ In that study, the authors found a significant reduction in systolic pressure $(-19 \mathrm{mmHg})$, diastolic pressure $(-7 \mathrm{mmHg})$, and mean arterial pressure $(-11 \mathrm{mmHg})$ after 8 weeks of handgrip training. Studies have shown that moderate handgrip IE reduces BP in normortensive ${ }^{15-22}$ and hypertensive ${ }^{15-24}$ subjects. Moreover, the information available in the literature on the acute effects of an IE session on post-isometric exercise hypotension (PIEH) in hypertensive older people is unclear. ${ }^{25-27}$ Additionally, IE may result in an increased BP correlating to duration of contraction..$^{25}$

Thus, the practice of IE could be a recommendation for older people with weakness or motor limitation, given that this type of capability is usually required to perform the activities of daily living and especially in situations related to clinical practice. ${ }^{12}$ Therefore, the purpose of this study was to investigate the cardiovascular responses to different intensities of IE, as well as the occurrence of PIEH in hypertensive elderly people being treated with antihypertensive medication.

\section{Patients and methods Sample}

After approval by the Research Ethics Committee of Mogi das Cruzes University (33/2009), twelve older (64 \pm 1 years) people who were physically inactive and had hypertension controlled by antihypertensive medication participated in this study. Exclusion criteria were: clinical diagnosis of diabetes mellitus, current smoker, organ damage, and musculoskeletal complications and/or cardiovascular alterations confirmed by physical test. All procedures were performed according to the Declaration of Helsinki. ${ }^{28}$

\section{Measures}

\section{Anthropometric parameters}

The anthropometric measures conformed to those previously reported by our group..$^{29-33}$ Height was measured to the nearest $0.1 \mathrm{~cm}$ using a Cardiomed ${ }^{\circledR}$ WCS stadiometer (Curitiba, Brazil). Body mass was measured to the nearest $0.1 \mathrm{~kg}$ using a Filizola Personal Line 150 scale (São Paulo, Brazil). Body mass index (BMI; $\mathrm{kg} / \mathrm{m}^{2}$ ) was calculated as follows: $\mathrm{BMI}=$ weight $/$ height $^{2}$. Body composition was determined using anthropometric measures.

\section{Exercise testing protocol}

All volunteers were submitted to a maximal treadmill walking test, using the modified Balke protocol. ${ }^{19} \mathrm{~A}$ twelve-lead SM 400 electrocardiograph (TEB, New York, NY, USA) was used to record the maximal heart rate (HR). Arterial BP was measured during the test using a sphygmomanometer (BP cuff) and stethoscope (both Becton Dickinson, New York, NY, USA). Participants were excluded in case of ST segment depression $>1 \mathrm{~mm}$, complex arrhythmias, or when ischemic symptoms were observed during exercise testing. $^{34}$

\section{$\mathrm{BP}$ and heart rate}

Systolic blood pressure (SBP), diastolic blood pressure (DBP), and mean arterial blood pressure (MAP) $(\mathrm{MAP}=\mathrm{DBP}+[\mathrm{SBP}-\mathrm{DBP}] / 3)$ and HR were measured before, during, and immediately after each IE training session using an automated noninvasive BP monitor (Microlife 3AC1-1PC, Microlife, Widnau, Switzerland). ${ }^{35}$ Rate-pressure product (RPP) was evaluated according to the following equation: $\mathrm{RPP}=\mathrm{HR} * \mathrm{SBP}$. The measurement was performed after the subjects completed each set (a total of four); the objective of this measurement was to guarantee that BP did not fall during the exercise session. ${ }^{4}$ All BP measurements were taken on the left arm. Individual cuffs were labeled with the ranges of arm circumferences. ${ }^{36}$ Pre-exercise BP did not exceed 160 and $100 \mathrm{mmHg}$ for SBP and DBP, respectively. During exercise, HR was continuously measured and recorded on a beat-by-beat basis using a Polar Vantage NV (Polar Electro, Oulu, Finland) HR recorder. Volunteers were also instructed to avoid the Valsalva maneuver during the entire movement, following American College of Sports Medicine guidelines. ${ }^{4}$ 
To evaluate the occurrence of PEH, BP, and HR were also measured in the sitting position (resting) at 5, 10, 15, 30, 45, and 60 minutes of post-exercise recovery.

\section{Maximal voluntary contraction}

Subjects were asked to refrain from eating, smoking, and ingesting caffeine and alcohol for at least 4 hours before testing. All volunteers participated in a battery of tests to determine their maximal voluntary contraction (MVC) using a handgrip dynamometer (Jamar Hydraulic Hand Dynamometer 5030 J1, Patterson Medical, Bolingbrook, IL, USA). Before the test, subjects underwent three familiarization sessions (two sets of 10 seconds each using the minimum weight allowed by the equipment separated by a 2-minute rest, in conformation with Schlüssel et $\mathrm{al}^{37}$ ) on nonconsecutive days. Following a brief warm-up, each subject's MVC value was determined as the highest value obtained of the three attempts. To guarantee objectivity, all tests were performed by the same researcher with the Valsalva maneuver.

\section{IE sessions}

After the MVC testing and standardization of the intervention workload, volunteers underwent two sessions of IHG exercise consisting of four sets of five contractions of a 10 -second duration each. Sessions were performed both at $30 \%$ of the MVC and $50 \%$ of the MVC, using a unilateral IHG protocol. Both interventions were compared with a control session without exercise. SBP and DBP were evaluated at rest (R), peak exercise (PE) and at 5, 10, 15, 30, 45, and 60 minutes post exercise.

The IE protocol was adapted from an earlier study that demonstrated significant reductions in arterial BP at rest after a chronic intervention. ${ }^{15}$ Upon arrival in the laboratory (between 13:00 and 16:00) after a light standard meal, subjects remained resting in sitting position for 20 minutes before starting the exercise. Subjects did not perform any physical activity for at least 24 hours before the evaluations and avoided caffeine or alcohol. During exercise, subjects received $15 \mathrm{~mL}$ of water per $\mathrm{kg}$ of body weight for water replacement. Exercise sessions were randomized and performed at least 72 hours apart. The laboratory temperature was maintained between $22.5^{\circ} \mathrm{C}$ and $25.8^{\circ} \mathrm{C}$ during all testing sessions.

\section{Statistical analyses}

All statistical analyses were performed using SPSS software (v 12.0; IBM, Armonk, NY, USA). Analysis of comparisons between groups over the periods was performed with two-way analysis of variance with repeated measures, followed by Kruskal-Wallis or Bonferroni's post-hoc test when appropriate. The D'Agostino-Pearson test was applied to Gaussian distribution analysis. Statistical significance was established at $P<0.05$. Data are expressed as mean \pm standard deviation.

\section{Results}

The anthropometric parameters, resting hemodynamics, and medications used are presented at Table 1. The maximal voluntary strength test did not differ between the right and left limbs. Additionally, there were no differences in hemodynamic parameters during the peak of contraction compared with the control situation, demonstrating that the test did not promote cardiovascular system overload, as shown in Table 2.

The changes in hemodynamic parameters before, during exercise peak, and isometric post-exercise are presented in Table 3. No changes were observed in hemodynamic parameters immediately after the end of the exercise protocol, despite exercise intensity. Similarly, no hemodynamic overload was identified during the exercise session intervals (Table 4).

\section{Discussion}

The main finding of this study was that no PEH was observed at any IHG exercise intensity. This is important because isometric sessions should not provoke acute cardiovascular responses. Li et al found no acute cardiovascular changes in coronary patients submitted to 3 minutes of

Table I Sample characteristics

\begin{tabular}{ll}
\hline Parameters & \\
Anthropometric parameters & \\
Weight $(\mathrm{kg})$ & $68 \pm 3$ \\
Height $(\mathrm{cm})$ & $157 \pm 2$ \\
BMI $\left(\mathrm{kg} / \mathrm{cm}^{2}\right)$ & $27 \pm \mathrm{I}$ \\
Hemodynamic parameters & \\
HR $(\mathrm{bpm})$ & $72 \pm 6$ \\
SBP $(\mathrm{mmHg})$ & $121 \pm 7$ \\
DBP $(\mathrm{mmHg})$ & $72 \pm 6$ \\
MAP $(\mathrm{mmHg})$ & $88 \pm 5$ \\
RPP $(\mathrm{bpm} * \mathrm{mmHg})$ & $8874 \pm 888$ \\
Medicine & \\
$\beta$-blocker & $75 \%$ \\
ACE inhibitor & $83 \%$ \\
Angiotensin II antagonist receptor & $50 \%$ \\
Diuretic & $58 \%$ \\
Calcium channel blocker & $50 \%$ \\
\hline
\end{tabular}

Note: Values expressed as the mean \pm standard deviation unless otherwise specified. Abbreviations: ACE, angiotensin-converting-enzyme; BMI, body mass index; DBP, diastolic blood pressure; HR, heart rate; MAP, mean arterial pressure; RPP, rate-pressure product; SBP, systolic blood pressure. 
Table 2 Maximal voluntary contraction parameters

\begin{tabular}{lccc}
\hline & Control & Right arm & Left arm \\
\hline $\begin{array}{l}\text { Maximal voluntary } \\
\text { contraction (kg) }\end{array}$ & & $25 \pm 3$ & $24 \pm 4$ \\
Hemodynamic parameters & & & \\
$\quad$ HR (bpm) & $74 \pm 5$ & $72 \pm 1$ & $71 \pm 1$ \\
SBP (mmHg) & $122 \pm 7$ & $126 \pm 1$ & $126 \pm 3$ \\
DBP (mmHg) & $74 \pm 3$ & $78 \pm 1$ & $77 \pm 2$ \\
MAP (mmHg) & $90 \pm 5$ & $94 \pm 1$ & $93 \pm 2$ \\
RPP (mmHg*bpm) & $9028 \pm 275$ & $9063 \pm 235$ & $8945 \pm 279$ \\
\hline
\end{tabular}

Note: Values expressed as the mean \pm standard deviation.

Abbreviations: DBP, diastolic blood pressure; HR, heart rate; MAP, mean arterial pressure; RPP, rate-pressure product; SBP, systolic blood pressure.

isometric contraction. ${ }^{38}$ This same response was found by Auerbach et al using the dead lift exercise at 50\% MVC sustained for 3 minutes in 18 heart transplant recipients. ${ }^{39}$

We may infer that even for IE involving large muscle mass, no hemodynamic abnormalities or electrocardiographic or clinical abnormalities that contraindicate this type of strength exercise would be presented by this population. ${ }^{27}$ Note that variables such as weather and load voltage are crucial points to be considered when IE is to be carried out. ${ }^{40,41}$ Further, the intensity used in this study was different from that used in other clinical studies, ${ }^{38}$ showing that the practice of IE under the conditions used in this study is safe and does not promote excessive elevation of BP in elderly women.

Significant changes in BP associated with IE were observed in the scientific literature, ${ }^{1-16,18-21}$ mostly in chronic studies, which justifies the proposal of the present research in analyzing the behavior of acute post-exercise BP. Besides, in these previously mentioned studies the IHG exercise was performed only at $30 \% \mathrm{MVC}$ and involved $4 \times 2$-minute bilateral ${ }^{15,18}$ or unilateral contractions ${ }^{26}$ with a rest period of 3 minutes or 1 minute, respectively, between contractions.

Recent studies have investigated the effects of acute IE in the elderly. Araújo et al, for example, examined the effects of IE on post-exercise BP in 41 elderly cardiac patients using $30 \% \mathrm{MVC}$ with four sets of 2 minutes of contractions. ${ }^{27}$ The authors concluded that after IHG exercise, BP and HR returned to baseline values after 1 minute of post-exercise recovery. These results are similar to our finding, in that, at 5 minutes of post-exercise recovery, no abnormality in cardiovascular parameters was observed in elderly women with controlled hypertension.

Millar et al investigated the acute effects of four IHG protocols on BP and neurocardiac reactivity. ${ }^{26}$ In that study, twelve healthy older subjects completed four bilateral 12-minute protocols (control, IHG1, IHG2, IHG3) on separate visits. The IHG1, IHG2, and IHG3 exercises consisted of $4 \times 2$-minute,

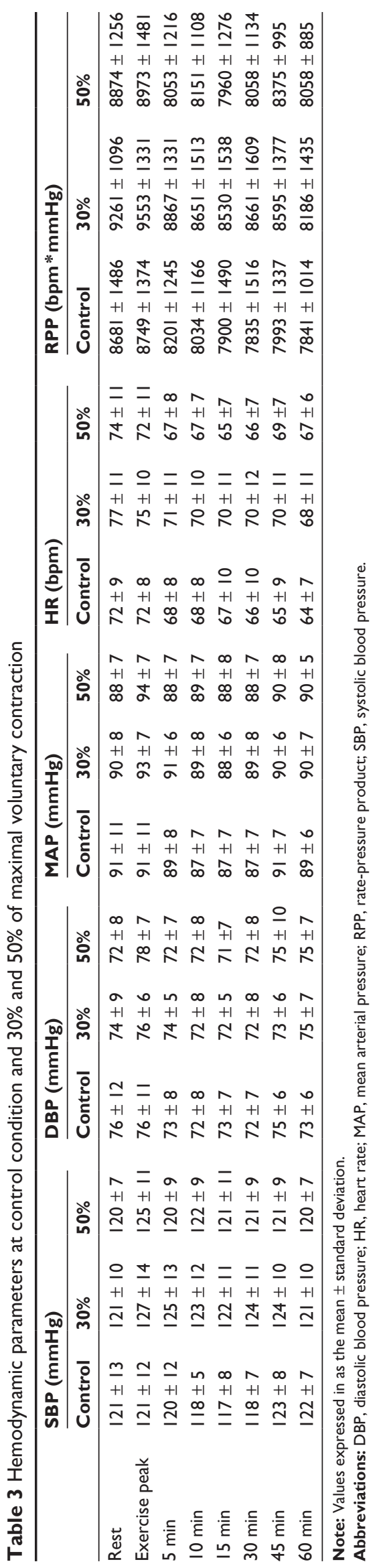




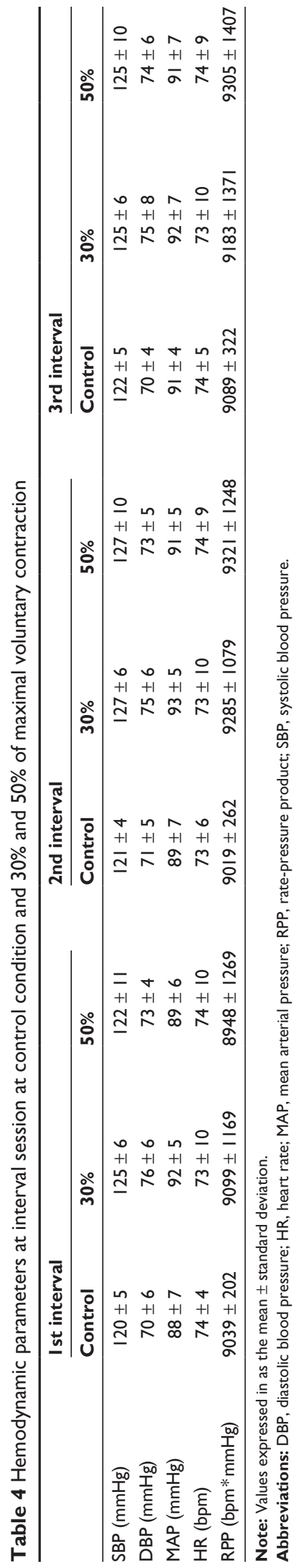

$8 \times 1$-minute, and $16 \times 30$-second isometric contractions, respectively, completed at $30 \% \mathrm{MVC}$, while the sham consisted of $4 \times 2$-minute contractions completed at $3 \%$ MVC. BP and neurocardiac modulation were assessed during each protocol and at $5,10,15,20,25$, and 35 minutes post exercise. In conclusion, recovery responses from rhythmic IHG appear independent of contraction duration and/or rest period between sets, but rather are related to contraction frequency and total duration of exercise. In addition, similar to our results, no difference in the BP or HR response after a single IHG session was verified in healthy older people not on regular antihypertensive medication.

Although studies have shown that hypotension postexercise may be of higher magnitude with mild to moderate physical activity than at high intensities ${ }^{42}$ it is not clear in the literature if the intensity of IE influences the magnitude or the rate of reduction of rest $\mathrm{BP}^{4}{ }^{4}$ This is because the available studies have often used intensity corresponding to $30 \%$ MVC, considered a moderate level. ${ }^{21}$ In our study, we found no reduction in $\mathrm{BP}$ after exercise, which can be explained by the low volume of protocols used; however, the workloads used were strongly associated with tasks of daily living. Our protocol involved four sets of five contractions of 10 seconds' duration each (total approximately 4 minutes) at 30\% and $50 \% \mathrm{MVC}$, which differs from the protocols used in other studies, ${ }^{16,18,26,43-45}$ in which four series of contractions for 2 minutes each, totaling approximately 8 minutes, were used.

In a similar study using a short-duration IE protocol, Kiveloff and Huber reported significant reductions ranging from 16 to $43 \mathrm{mmHg}$ in resting SBP and from 2 to $24 \mathrm{mmHg}$ in resting DBP as a result of 5-8 weeks of static exercise (6-second contractions for all large muscle groups, $3 \cdot \mathrm{d}^{-1}, 5 \mathrm{~d} \cdot \mathrm{wk}^{-1}$ ) in hypertensive adults. ${ }^{46}$ However, unfortunately, the methodological differences - for example, the fact that adult hypertensive individuals were submitted to chronic IE - compromise any eventual comparison between their results and ours.

Another important feature is the volume of training. Our study used half the volume ( $\sim$ minutes) of IE than that used in other studies. Mediano et al concluded that a higher training volume resistance exercise session can promote reductions in SBP level in medicated hypertensive older individuals. ${ }^{47}$ In our study, the absence of HPE in older women with IHG exercise may be related to increased vascular resistance and large-artery stiffness caused by aging.

\section{Conclusion}

Our data lead us to conclude that older women with controlled hypertension who undertake IE of short duration at intensities of $30 \%$ and $50 \%$ MVC do not present any exacerbated BP 
responses to exercise and do not show PEH. Thus, the exercise was safe for our patients. Similar studies should be conducted on patients with elevated BP. Further, as exercise physiologists are called upon to perform strengthening exercises for elderly people with cardiovascular disease, these findings may be useful for the monitoring of cardiovascular responses in such patients during the practice of IE.

\section{Acknowledgments}

We would like to thank Mr. Zenon Aranha Filho of the Faculty of Physical Education of the University of Mogi das Cruzes. We additionally acknowledge the assistance of the Salvape, and the Trainer Gym, Mogi das Cruzes. This study was supported by grants from Fundação de Amparo a Pesquisa do Estado de São Paulo-FAPESP (2011/03528-0) and Conselho Nacional de Pesquisa e Tecnologia-CNPq.

\section{Disclosure}

The authors declare no conflicts of interest in this work.

\section{References}

1. Franco V, Oparil S, Carretero OA. Hypertensive therapy: Part I. Circulation. 22 2004;109(24):2953-2958.

2. Pescatello LS, Franklin BA, Fagard R, Farquhar WB, Kelley GA, Ray CA; American College of Sports Medicine. American College of Sports Medicine position stand. Exercise and hypertension. Med Sci Sport Exerc. 2004;36(3):533-553.

3. Diretriz de Reabilitação Cardíaca [Guidelines for cardiac rehabilitation]. Arq Brasi Cardiol. 2005;84(5): 431-440. Portuguese.

4. Braith R, Stewart K. Resistance exercise training: its role in the prevention of cardiovascular disease. Circulation. 2006;113(22):2641-2650.

5. Scher LM, Nobre F, Lima NK. O papel do exercício físico na pressão arterial em idosos. The role of the physical exercise on blood pressure in older individuals. Revista Brasileira de Hipertensão. 2008;15(4): 228-231. Portuguese and English.

6. Laterza MC, Rondon MU, Negrão C. Efeito anti-hipertensivo do exercício. The antihypertensive effect of exercise. Rev Brasi Hipertensão. 2007;14(2):104-111. Portuguese and English.

7. O'Connor P, Bryant C, Veltri J, Gebhardt S. State anxiety and ambulatory blood pressure following resistance exercise in females. Med Sci Sport Exercise. 1993;25(4):516-521.

8. Kelley GA, Kelley KS. Progressive resistance exercise and resting blood pressure: A meta-analysis of randomized controlled trials. Hypertension. 2000;35(3):838-843.

9. Costa JB, Gerage AM, Gonçalves CG, Pina FL, Polito MD. Influência do estado de treinamento sobre o comportamento da pressão arterial após uma sessão de exercícios com pesos em idosas hipertensas. Influence of the training status on the blood pressure behavior after a resistance training session in hypertensive older females. Revista Brasileira de Medicina do Esporte. 2010;6(2):103-106. Portuguese and English.

10. Moraes MR, Bacurau RF, Ramalho JD, et al. Increase in kinins on post-exercise hypotension in normotensive and hypertensive volunteers. Biol Chem. 2007;388(5):533-540.

11. Moraes MR, Bacurau RF, Casarini DE, et al. Chronic conventional resistance exercise reduces blood pressure in stage 1 hypertensive men. J Strength Cond Res. 2012;26(4):1122-1129.

12. Cornelissen VA, Fagard RH, Coeckelberghs E, Vanhees L. Impact of resistance training on blood pressure and other cardiovascular risk factors: a meta-analysis of randomized, controlled trials. Hypertension. 2011;58(5):950-958.
13. PontesFLJr,MutarelliMC,NavarroF, MoraesMR, Araújo RC,BacurauRF. Resposta cardiovascular materna e fetal ao exercício isométrico Maternal and fetal cardiovascular response to isometric exercise. Revista Brasileira de Ciência e Movimento. 2006;14(3):15-22. Portuguese.

14. McGowan CL, Visocchi A, Faulkner M, et al. Isometric handgrip training improves local flow-mediated dilation in medicated hypertensives. Eur J Applied Physiol. 2007;99(3):227-234.

15. Wiley RL, Dunn CL, Cox RH, Hueppchen NA, Scott MS. Isometric exercise training lowers resting blood pressure. Med Sci Sports Exerc. 1992;24(7):749-754.

16. Ray CA, Carrasco DI. Isometric handgrip training reduces arterial pressure at rest without changes in sympathetic nerve activity. $\mathrm{Am} \mathrm{J}$ Physiol. 2000;279(1):H245-H249.

17. Howden R, Lightfoot JT, Brown SJ, Swaine IL. The effects of isometric exercise training on resting blood pressure and orthostatic tolerance in humans. Exp Physiol. 2002;87(4):507-515.

18. Taylor AC, Mccartney N, Kamath MaV, Wiley RL. Isometric training lowers resting blood pressure and modulates autonomic control. Med Sci Sports Ex. 2003;35(2):251-256.

19. McGowan C, Visocchi A, Faulkner M, Rakobowchuk M, McCartney N, MacDonald M. Isometric handgrip training improves blood pressure and endothelial function in persons medicated for hypertension. Physiologist. 2004;47:285.

20. Millar PJ, Bray SR, McGowan CL, MacDonald MJ, McCartney N. Effects of isometric handgrip training among people medicated for hypertension: a multilevel analysis. Blood Pres Monit. 2007;12(5): 307-314.

21. Wiles JD, Coleman DA, Swaine IL. The effects of performing isometric training at two exercise intensities in healthy young males. Eur J Applied Physiol. 2009;108(3):419-428.

22. Devereux GR, Wiles JD, Swaine IL. Reductions in resting blood pressure after 4 weeks of isometric exercise training. Eur J Applied Physiol. 2010;109(4):601-606.

23. MacDonald JR. Potential causes, mechanisms, and implications of post exercise hypotension. J Hum Hypertens. 2002;16(4):225-236.

24. Millar PJ, Paashuis A, McCartney N. Isometric handgrip effects on hypertension. Curr Hypertens Rev. 2009;5:54-60.

25. Williams MA, Haskell WL, Ades PA, et al. Resistance exercise in individuals with and without cardiovascular disease: 2007 update. Circulation. 2007;116:572-584.

26. Millar PJ, MacDonald MJ, Bray SR, McCartney N. Isometric handgrip exercise improves acute neurocardiac regulation. Eur J Appl Physiol. 2009;107(5):509-515.

27. Araújo CG, Duarte CV, Gonçalves Fde A, Medeiros HB, Lemos FA, Gouvêa AL. Hemodynamic responses to an isometric handgrip training protocol. Arq Bras Cardiol. 2011;97(5):413-419.

28. World Medical Association (WMA). World Medical Association Declaration of Helsinki: Ethical Principles for Medical Research Involving Human Subjects. Ferney-Voltaire: WMA; 2008. Available from: http:// www.wma.net/en/30publications/10policies/b3/17c.pdf. Accessed February 12, 2013.

29. Bocalini DS, Lima LS, Andrade S, et al. Effects of circuit-based exercise program on the body composition of elderly obese women. Clin Interv Aging. 2012;7:551-556.

30. Bocalini DS, Serra AJ, Rica RL, Dos Santos L. Repercussions of training and detraining by water-based exercise on functional fitness and quality of life: a short-term follow-up in healthy older women. Clinics (San Paulo). 2010;65(12):1305-1309.

31. Bocalini DS, Serra AJ, dos Santos L. Moderate resisted exercise attenuates the loss bone density and increments the functional fitness at postmenopausal women. J Aging Res. 2010. doi:10.4061/2010/ 760818.

32. Bocalini DS, Serra AJ, dos Santos L. Physical exercise improves the functional capacity and quality of life in patients with heart failure. Clinics (San Paulo). 2008;63(4):437-442.

33. Bocalini DS, Serra AJ, Murad N, Levy RF. Water- versus land-based exercise effects on physical fitness in older women. Geriatr Gerontol Int. 2008;8(4):265-271. 
34. Josephson RA, Shefrin E, Lakatta EG, Brant LJ, Fleg JL. Can serial exercise testing improve the prediction of coronary events in asymptomatic individuals? Circulation. 1990;81(1):21-24.

35. Topouchian JA, El Assaad MA, Orobinskaia LV, El Feghali RN, Asmar RG. Validation of two devices for self-measurement of brachial blood pressure according to the International Protocol of the European Society of Hypertension: the SEINEX SE-9400 and the Microlife BP 3AC1-1. Blood Press Monit. 2005;10: 325-331

36. Pickering TG, Hall JE, Appel LJ, et al. Recommendations for blood pressure measurement in humans and experimental animals: part 1: blood pressure measurement in humans: a statement for professionals from the Subcommittee of Professional and Public Education of the American Heart Association Council on High Blood Pressure Research. Circulation. 2005;111(5):697-716.

37. Schlüssel MM, Anjos LA, Kac G. A dinamometria manual e seu uso na avaliação nutricional. Hand grip strength test and its use in nutritional assessment. Revista de Nutrição. 2008;21(2):223-235. Portuguese.

38. Li J, Zhao W, Zhou S, Lu X, Zhang Q. Relationship between isometric exercise and myocardial ischemia in patients with coronary artery disease: an Echo-Doppler study. Chin Med J (Engl). 2000;13(6):493-497. Chinese.

39. Auerbach I, Tenenbaum A, Motro M, Stroh CI, Har-Zahav Y, Fisman EZ Blunted responses of doppler-derived aortic flow parameters during whole-body heavy isometric exercise in heart transplant recipients. J Heart Lung Transplant. 2000;19(11):1063-1070.
40. Ray CA, Mahoney ET, Hume KM. Exercise-induced muscle injury augments forearm vascular resistance during leg exercise. Am J Physiol. 1998;275(2 Pt 2):H443-H447.

41. Stewart JM, Montgomery LD, Glover JL, Medow MS. Changes in regional blood volume and blood flow during static handgrip. Am J Physiol Heart Circ Physiol. 2007;292(1):H215-H223.

42. Moraes MR, Bacurau RF, Simões HG, et al. Effect of 12 weeks of resistance exercise on post-exercise hypotension in stage 1 hypertensive individuals. J Hum Hypertens. 2012;26(9):533-539.

43. Boutcher SH, Stocker D. Cardiovascular responses to light isometric and aerobic exercise in 21- and 59-year-old males. Eur J App Physiol Occup Physiol. 1999;80(3):220-226.

44. Kamiya A, Michikami D, Fu Q, et al. Static handgrip exercise modifies arterial baroreflex control of vascular sympathetic outflow in humans. Am J Physiol Regul Integr Comp Physiol. 2001;281(4): R1134-R1139.

45. McGowan CL, Levy AS, McCartney N, MacDonald MJ. Isometric handgrip training does not improve flow-mediated dilation in subjects with normal blood pressure. Clin Sci (Lond). 2007;112(7):403-409.

46. Kiveloff B, Huber O. Isometrics in lowering blood pressure. JAMA. 1973;223(5):559.

47. Mediano MF, Paravidino V, Simão R, Pontes FL, Polito MD Comportamento subagudo da pressão arterial após o treinamento de força em hipertensos controlados [Subacute behavior of the blood pressure after power training in controlled hypertensive individuals]. Revista Brasileira de Medicina do Esporte. 2005;11(6):99-104. Spanish.
Clinical Interventions in Aging

\section{Publish your work in this journal}

Clinical Interventions in Aging is an international, peer-reviewed journal focusing on evidence-based reports on the value or lack thereof of treatments intended to prevent or delay the onset of maladaptive correlates of aging in human beings. This journal is indexed on PubMed Central, MedLine, the American Chemical Society's 'Chemical Abstracts

\section{Dovepress}

Service' (CAS), Scopus and the Elsevier Bibliographic databases. The manuscript management system is completely online and includes a very quick and fair peer-review system, which is all easy to use. Visit http://www.dovepress.com/testimonials.php to read real quotes from published authors. 